\title{
Introduction to the Special Issue: What are Religious Beliefs?
}

\author{
Thomas J. Coleman III \\ Centre for Advances in Behavioural Science, Coventry University \\ Colema56@uni.coventry.ac.uk
}

Jonathan Jong

Centre for Advances in Behavioural Science, Coventry University ac1223@coventry.ac.uk

Valerie van Mulukom

Centre for Advances in Behavioural Science, Coventry University ac2492@coventry.ac.uk

The question of how religion ought to be defined has occupied social scientists for well over a century, arguably beginning with reactions against E.B. Tylor's (1871) "minimal definition" of religion as the belief in spiritual beings. Social scientists of religion are all too familiar with the debates over emic and etic approaches to defining religion, as well as the pros and cons of substantive versus functionalist definitions. More recently, cognitive scientists of religion seem to have just taken Tylor as their starting point, treating the belief in supernatural agents as their central explanandum (e.g., Barrett and Lanman 2008; Boyer 1994; Guthrie 1993). "Belief" is no less of a theoretical term than is "religion", and no less deserving of attention, interrogation, and clarification by the scholars who use it. With very few exceptions, critical discussion of this central concept within the psychological science of religion has been absent (Lanman 2008).

As Jong (2013) observes, theoretical understandings of belief are underdeveloped in the psychological sciences more broadly, in contrast to the research literatures on other constructs like emotions (e.g., Barrett \& Russell 2015; Ekman \& Davidson 1995) and attitudes (e.g., Eagly \& Chaiken 1993; Petty, Fazio, \& Briñol 2009). Perhaps unsurprisingly, given their normative epistemological concerns, philosophers and theologians have done considerably more groundwork in this area (e.g., Bishop 2007; Cohen 1995; Nottelmann 2013), but it is unclear if the fruits of their labour will trickle down in such a way as to benefit social and psychological scientists. The goal of this special issue is therefore to 
bridge the gap between the humanities and the sciences, to begin a long overdue conversation about the possible nature of religious belief.

\section{Six Views on the Nature of Religious Belief}

In his "Beliefs are object-attribute associations of varying strength," social psychologist Jonathan Jong begins by considering how social and cognitive psychological theories about attitudes might inform the analytic philosophical literature on propositional attitudes, of which belief is a paradigmatic example. Jong's account of beliefs - in terms of associations between concepts - does not treat religious beliefs any differently from beliefs in other domains in terms of their cognitive structure. Religious beliefs are just beliefs about gods and other religious entities or events; like other beliefs, they are cognitive associations between object concepts (e.g., God) and existential (e.g., real, imaginary) or truth-value (e.g., true, false) concepts. Therefore, the same questions about other kinds of beliefs - about measurement; stability and change; relationships to identity and behaviour - all also apply to religious beliefs. This is not to suggest that the answers to such questions will be the same across different domains of belief: religious beliefs may be more or less tentatively held than other beliefs; they may be more or less chronically accessible than other beliefs; they may be more or less predictive of behaviour or tied up with social identity than other beliefs or amenable to modification. These are all empirical questions, to be answered in part using tools designed to measure and manipulate beliefs more broadly.

Psychological anthropologist Tanya Luhrmann does draw a distinction between religious and other kinds of beliefs in her essay "The Faith Frame: or, belief is easy, faith is hard". She points out that common language about religious beliefs differs from language about other beliefs; religious beliefs are tied to identity; religious explanations function differently from nonreligious ones; religious beliefs are not evaluated as other beliefs are; and they are highly context-sensitive. Building on these observations, Luhrmann posits a "faith frame" and an "everyday frame", different modes of evaluating experience and evidence, like the kind of difference Gregory Bateson (1955) drew between play and non-play. When someone of faith thinks about God, they evaluate God-related sentences differently, and draw different interferences, from the way they evaluate non-faith related claims. People of faith may say that God is omnipotent, for example, but, she argues, they do not really behave that way.

Luhrmann's approach builds on philosopher Neil Van Leeuwen's previous work (e.g., 2014, 2017b) on religious credence, on which he elaborates in his 
contribution to this special issue, "The factual belief fallacy". The paper begins as a response to critics - chiefly Boudry and Coyne (2016) and Levy (2017) - and is therefore part of an on-going discussion about whether and how religious and everyday beliefs should be distinguished from one another (see also Van Leeuwen 2016, 2017a). It then proceeds, as Jong's paper did, by discussing a variety of attitudes that people take toward their mental representations and the objects to which they refer. Unlike Jong, however, Van Leeuwen distinguishes between two different cognitive attitudes that are commonly called beliefs, namely factual beliefs and religious credences. However, the difference between these is not their structure but the way they are processed. By this, Van Leeuwen refers, in this paper, mainly to the way they are activated to guide our behaviours: (religious) credences are practical setting dependent, triggered only in very specific contexts, whereas (factual) beliefs are practical setting independent.

Despite their on-going disagreement about the nature of religious belief, philosopher Neil Levy draws a similar distinction as Van Leeuwen's practical setting (in)dependence distinction; indeed, Levy provides an explanation for practical setting dependence. In "In Praise of Outsourcing", he argues that belief activation is context sensitive to the extent that it is coupled to external cues. Some religious beliefs are thus coupled, and are therefore only activated when the relevant cues are present. Crucially, however, "coupled representations" and "religious representations" fail to be coextensive categories; contra Van Leeuwen, the relationship between them is such that one should not be treated as a heuristic for the other.

Theologian Tobias Tan also focusses on the context sensitivity of religious beliefs, but not as a means of distinguishing religious from other kinds of belief. Rather, in his "William James and Embodied Religious Belief", Tan considers the implications of a view of cognition that attends to the contextual, action-oriented, and affect-laden nature of beliefs in general. He observes that many findings in the cognitive science of religion (CSR) literature are already consistent with this view, and encourages the field to extend itself further in this direction. Along similar lines as Tan, philosopher Hans van Eyghen also argues for a more embodied, embedded, and distributed account of religious belief than the ones he has found in CSR.

\section{Toward Rapprochement}

The purpose of scientific definition is to guide research, by paving the way toward operationalisation and measurement and by posing novel questions and 
hypotheses. Taken together, these contributions to this special issue do suggest several new lines of inquiry. The central disagreement - over the relationship between religious and everyday beliefs - turns out to be an empirically tractable one. Van Leeuwen claims that some beliefs are practical setting dependent, and others are practical setting independent. Levy claims that some beliefs are coupled to external cues, and others are not. Levy further claims that coupling explains practical setting dependence. Their central disagreement is over the heuristic value of associating religious beliefs with one side of either distinction. Van Leeuwen's distinction between religious credences and factual beliefs requires that religious beliefs are much more likely to be practical setting dependent than independent, and also that practical setting dependent beliefs are much more likely to be religious than mundane. If the overlap between the religious and practical setting dependent is too thin, then they fail to serve as useful proxies for one another.

Regardless of how this debate turns out, the distinctions drawn by Luhrmann, Van Leeuwen, and Levy also raise questions about the conditions under which the cognitive states in question obtain. What are the relevant inputs for the faith frame to be activated? Why are some beliefs practical setting dependent and other not? How do representations get coupled? Given that Tan's and van Egyhen's contributions argue from a general perspective on cognition, they not only challenge researchers to re-conceptualise religious beliefs but beliefs more broadly: perhaps our everyday or practical setting independent or uncoupled beliefs are also more contextual, goal-directed, socially-embedded, and affect-laden than we have previously noticed. These are all empirical questions to be attended to.

\section{References}

Barrett, Justin L., and Jonathan A. Lanman. 2008. "The Science of Religious Beliefs". Religion 38 (2): 109-124. doi:10.1016/j.religion.2008.01.007.

Barrett, Lisa Feldman, and James A Russell. 2015. The Psychological Construction of Emotion. New York: The Guilford Press.

Bateson, Gregory. 1955. "A Theory of Play and Fantasy". Psychiatric Research Reports 2: 39-51.

Bishop, John. 2007. Believing By Faith. Oxford: Clarendon Press.

Boudry, Maarten, and Jerry Coyne. 2016. "Disbelief in Belief: On the Cognitive Status of Supernatural Beliefs”. Philosophical Psychology 29 (4): 601-615. doi:10.1080/o951508 9.2015.1110852. 
Boyer, Pascal. 1994. The Naturalness of Religious Ideas. Berkeley: University of California Press.

Cohen, L. Jonathan. 1995. An Essay on Belief and Acceptance. Oxford: Clarendon Press.

Eagly, Alice H, and Shelly Chaiken. 1993. The Psychology of Attitudes. Belmont, Calif.: Wadsworth Cengage Learning.

Ekman, Paul, and Richard J Davidson. 1995. The Nature of Emotion. New York: Oxford University Press.

Guthrie, Stewart. 1993. Faces In The Clouds. New York: Oxford University Press.

Jong, Jonathan. 2013. "Implicit Measures in the Experimental Psychology of Religion". In A New Science of Religion, 65-78. New York: Routledge.

Lanman, Jonathan. 2008. "In Defence of 'Belief': A Cognitive Response to Behaviourism, Eliminativism, and Social Constructionism”. Issues in Ethnology and Anthropology $3(3): 49-62$.

Nottelmann, Nikolaj. 2013. New Essays on Belief. New York, N.Y.: Palgrave Macmillan.

Petty, Richard E, Russell H Fazio, and Pablo Briñol. 2009. Attitudes. New York: Psychology Press.

Tylor, E.B. 1871. Primitive Culture: Researches into the Development of Mythology, Philosophy, Religion, Art, and Custom. London: John Murray.

Van Leeuwen, Neil. 2016. "Beyond Fakers and Fanatics: A Reply”. Philosophical Psychology 29 (4): 616-621. doi:10.1080/09515089.2016.1141400.

Van Leeuwen, Neil. 2017a. “Do Religious 'Beliefs' Respond to Evidence?". Philosophical Explorations 20 (sup1): 52-72. doi:10.1080/13869795.2017.1287294.

Van Leeuwen, Neil. 2014. "Religious Credence is not Factual Belief". Cognition 133 (3): 698-715. doi:10.1016/j.cognition.2014.08.015.

Van Leeuwen, Neil. 2017b. “Two Paradigms for Religious Representation: The Physicist and the Playground (A Reply to Levy)". Cognition 164: 206-211. doi:10.1016/j .cognition.2017.03.021. 